\title{
OPPY ON THE ARGUMENT FROM CONSCIOUSNESS: A REJOINDER
}

\author{
J. P. MORELAND
}

Biola University

Graham Oppy is not persuaded by my argument for God from consciousness (hereafter, AC) (Moreland 2008; cf. Moreland 2009a, 2009b; Oppy 2011). This is hardly surprising, coming from a man who, upon assessing the impact of the explosion of sophisticated literature in defense of theism over the past twenty-five years, claims that the probability of theism is still so low as to approximate zero (Oppy: p. 195)! Oppy raises dozens of points against my views, and I cannot respond to all of them here. Instead, I shall limit my remarks to those I take to be central to the issues relevant to my main thesis. Accordingly, I shall respond to his criticisms of my presentation of three forms of $\mathrm{AC}$, and interact with his claims about theism, consciousness and emergent chemical properties.

\section{THREE FORMS OF AC}

Oppy opines that we cannot argue from regular correlations of mental and physical states to theism by way of an inference to the best explanation. He supports this claim in two ways. First, to warrant such an inference, we need to factor in other theoretical virtues (e.g., the ontological, ideological and other costs of theistic explanation) and an assessment of how well theistic explanation comports with other well-established theories. Second, he says it is not clear just how theism does explain these correlations. He illustrates this problem with a thought experiment in which European explorers come to Australia, find the locals in possession of advanced mathematical knowledge, and in an attempt to explain this possession, rest content with the following: "It is hardly surprising that 
these abilities should exist in finite consciousness, since they already exist in an unembodied mind, viz. God" (Oppy: p. 194).

I have three responses to Oppy's first argument. First, it is just not true that successful inferences to the best explanation (IBEs) must have access to all the information he mentions before such an inference is warranted. If such were required, successful inferences to the best explanation could hardly ever be made because access to all, or even most, of such factors is seldom available. Instead, IBEs are often based on basic intuitions, e.g., tacit knowledge, of the relative fittingness/informativeness of two or more rival hypotheses and explanatory data. Attempts to formalize the psychology of discovery or the epistemology of justification here have failed, yet IBEs are successfully done all the time. Oppy's requirements are far too skeptical. Moreover, just because his intuitions about the theistic hypothesis and IBE are negative, it does not follow that they ought to be such or that others will not draw a different conclusion. Indeed, one of the key factors in leading Anthony Flew from atheism to theism was precisely the inductive evidence, most likely in the form of an IBE, regarding finite consciousness and relevant facts concerning it (Flew 2007: pp. 124-32, 161-65, 173-83). I believe that as AC gets more widely discussed, Oppy's form of extreme skepticism will not be prevalent, though I could be mistaken here.

Second, according to the leading expert on IBE-Peter Liptonwhen specific virtues-e.g., scope, unification, simplicity, treatment of contrastive "why" questions-are employed to assess an IBE, they are directly relevant to the loveliness of the hypothesis (its ability to facilitate understanding of why the data obtain and remove our puzzlement about them), and not its overall likelihood (Lipton 2000). By contrast, the specific virtues listed by Oppy seem relevant to overall likelihood, not loveliness with respect to data alone, and, thus, they are most likely irrelevant to cases of IBE. This leads to my third point.

Oppy seems to confuse factors relevant to IBE with those relevant to an overall assessment of the worth of a hypothesis. It could easily be the case that one could offer a successful IBE for a hypothesis relative to a specific range of facts, while that same hypothesis was judged ultimately inadequate in light of all the factors relevant to its assessment. My project was the former, not the latter, and so even if theism is judged inferior to 
naturalism in light of all the relevant considerations Oppy proffers, AC could still be a successful IBE.

What about Oppy's second argument regarding the lack of clarity of theistic explanation of mental/physical correlations? In my book I develop two points relevant to theistic explanation in this regard. For one thing, on theism, the basic being exemplifies mental properties, so the theist does not have the problem of getting something from nothing (the exemplification of mental properties from the mere rearrangement of brute matter). If, in the beginning were the particles, you have a problem with the appearance of the mental in the first place, a problem that numerous naturalists acknowledge. The theist is in no such pickle here. Second, I develop the details of personal explanation, and claim that it is within the motives, intentions, and causal powers of God to bring about mental states and their regular correlation with brain states.

Remember, it is not a central part of personal explanation, as opposed to, say, causal explanation in the hard sciences, to answer a "how" question regarding the means by which an agent brings about an end, especially when the agent's act was a basic one, as the theist will claim regarding God's action in creating and sustaining mental facts and associated correlations. Personal explanation follows its own inner logic, and it can hardly be faulted for being unclear by employing standards suitable to alternative models of explanation.

I have two things to say regarding Oppy's thought experiment. First, his claim that it is a weak explanation to appeal to God's faculties to explain, say, the existence of finite, e.g., mathematical abilities, is wrong. I cannot develop the point, but Thomas Nagel has acknowledged the problem here for the atheist, along with the availability of a theistic explanation of human reasoning abilities (Nagel 1997: pp. 128-33). Victor Reppert (Reppert 2009) and Alvin Plantinga (Plantinga 1993) have developed detailed defenses of this argument. Those defenses are hardly examples of a "low standard of good enough explanation."

Second, Oppy confuses an explanation of the precise direction taken by a culture with regard to developed mental abilities (which would appeal to the history, practices, etc. of the people in question), given that basic abilities exist, with an explanation of how basic mental states and correlations could exist in the first place. AC involves the latter and his thought experiment is simply irrelevant to that project. 
Oppy moves to a criticism of my C-inductive Bayesian version of AC. I shall briefly respond to his specific criticisms, and then step back and say what I believe is the key issue in this form of the argument.

Regarding the prior probability of theism relative to consciousness $(\operatorname{Pr}(\mathrm{T}))$, I claim that it is higher than many naturalists think, and support my claim by citing the explosive growth for twenty-five years of sophisticated defenses of theism of which many naturalists are unaware (I agree here with naturalist Quentin Smith; see Smith 2001). Oppy retorts that the history of philosophy is replete with sophisticated defenses of claims to which we now give little credence and, moreover, even in light of this literature, $\operatorname{Pr}(\mathrm{T})$ approximates zero.

I think Oppy's remarks are uncharitable and unconvincing. Obviously, in a book with a specific focus on AC, I could not undertake to provide a thorough-going defense of theism. Instead, I cite the presence of a vast amount of relevant recent literature with which many naturalists are unfamiliar. I certainly don't believe the mere existence of this literature establishes the truth of theism, and it is uncharitable to think otherwise. But it hardly follows that the plausibility of a viewpoint is not related to the volume and quality of defenses of that viewpoint. Think of what the epistemic situation would be if no one were defending theism and contrast that situation with the actual state of play. Surely the latter adds some support to theism. Moreover, my main point was that many naturalists working in the philosophy of mind (Oppy notwithstanding) take dismissive attitudes towards theism as though there were no sophisticated defenses of it. The widespread presence of such defenses makes such an attitude intellectually irresponsible, and that was, and is, my central point.

Regarding the probability of finite consciousness given theism $(\operatorname{Pr}(\mathrm{C} / \mathrm{T}))$, I claim that (1) consciousness is exemplified by the basic entity, given theism, so there is no problem with giving an account of where conscious properties could come from so as to be available for subsequent exemplification, and (2) qua person, God would have reasons to create other conscious beings because persons are communal in nature and love to create other persons. Oppy replies that there are serious conceptual problems with the very idea of a disembodied mind and, moreover, "we all know people who are not interested in meaningful relationships with others and who have no desire at all to bring other people into being" (Oppy: p. 196). 
The first claim strikes me as incredible. To make one point here, there is a vast and, in my view, convincing literature that disembodied existence is actual in near death experiences (See Long 2010). But what seems beyond reasonable doubt is that the vast majority of people, including educated people, rightly take these accounts as coherent and possibly true. Based on strong conceivability, from the first-person perspective, there is no problem with the possibility of me continuing to exist with such a perspective without a body.

It is hard to take the second claim seriously. For one thing, it is surely more natural and probable that a person will want meaningful relationships (and children) than not; thus, upon meeting a new person, one is prima facie justified in thinking these will be true of the person in question, unless an overriding defeater is discovered, and the same epistemic situation obtains in contemplating a possible person, including God. Further, if we note that the person in question is loving and generous, as is the case with God on the biblical conception, then it would be even more likely that such a person would desire meaningful relationships with others and to bring others into existence.

Next, Oppy responds to my following point: "[I]t is almost impossible for advocates of a naturalistic worldview to avoid admitting that these phenomena are explanatorily recalcitrant for them, and must be admitted as brute facts . . . And this is to admit that $\operatorname{Pr}(\mathrm{C} / \mathrm{N})$ is very, very low indeed (Moreland: p. 34)." Here is Oppy's response:

"We are supposing that ' $\mathrm{N}$ ' is the claim that naturalism is true, and ' $\mathrm{C}$ ' is the claim that 'conscious properties are regularly correlated with physical features'. What is the relationship between $\mathrm{C}$ and $\mathrm{N}$ ? A natural thought, given Moreland's characterization, is that $\mathrm{N}$ entails that it is a brute fact whether $\mathrm{C}$. But if $\mathrm{N}$ entails that it is a brute fact whether $\mathrm{C}$, then it is not the case that $\operatorname{Pr}(\mathrm{C} / \mathrm{N})$ is very, very low unless it is also the case that $\operatorname{Pr}(\mathrm{C})$ is very, very low. After all, N's entailing that it is a brute fact whether $\mathrm{C}$ surely ensures that $\mathrm{N}$ and $\mathrm{C}$ are probabilistically independent. . (Oppy: p. 196)."

In the broader context of my book, I think that my cited paragraph above is clear, but I admit that there is an ambiguity in my meaning if the paragraph is taken on its own, and I am happy to have the chance to clarify my point here. Oppy seems to be criticizing my claim that because $\mathrm{N}$ has no explanatory power with respect to $\mathrm{C}$, then $\operatorname{Pr}(\mathrm{C} / \mathrm{N})$ 
is very low. Now Oppy is correct to point out that two propositions can be explanatorily independent without being improbable with respect to each other. However, key to Oppy's criticism is his claim that "N's entailing that it is a brute fact whether $\mathrm{C}$ surely ensures that $\mathrm{N}$ and $\mathrm{C}$ are probabilistically independent. . ." It would follow from this that it makes not the slightest difference to our expectation of $\mathrm{C}$ whether $\mathrm{N}$ is true or false, and throughout my book, I make clear that this is not my view.

In my book, I actually deny that $\mathrm{N}$ entails that $\mathrm{C}$ is a brute fact. Instead, I claim that for various reasons (e.g., $\mathrm{N}$ provides absolutely no resources for predicting or explaining $\mathrm{C}), \operatorname{Pr}(\mathrm{C} / \mathrm{N})$ approximates zero. Thus, $\mathrm{N}$ strongly suggests that $\mathrm{C}$ does not exist, and a reductive or eliminative strategy will be employed to support this claim. Thus, the probabilities of $\mathrm{C}$ and $\mathrm{N}$ are not independent. In the isolated paragraph above, by saying that naturalism must acknowledge mental phenomena as brute facts, I meant to underscore their bruteness-their utter inexplicability and, therefore, (likely) non-existence-not their factuality, though I admit my meaning was not clear.

In my book, I provide a number of reasons to think that naturalists should deny the existence of irreducible consciousness. I am far from alone in this judgment. In fact, many-indeed, most-naturalist philosophers of mind have been strict physicalists. On the eve of the demise of logical positivism and the analytical behaviorism it funded, one of the fathers of the resulting stream of physicalism, J. J. C. Smart, paradigmatically noted: "It seems to me that science is increasingly giving us a viewpoint whereby organisms are able to be seen as physicochemical mechanisms. ... There does seem to be, so far as science is concerned, nothing in the world but increasingly complex arrangements of physical constituents. All except for one place: in consciousness ... I just cannot believe that this can be so. That everything should be explicable in terms of physics . . except the occurrence of sensations seems to me to be frankly unbelieveable" (Smart 1959: p. 61).

At this point, I want to step back from analyzing Oppy's specific criticisms and make a general point about the central issue in a Bayesian form of AC. Recall that in the early days of emergentism in the eighteenth and early nineteenth centuries, emergent properties were characterized epistemically, viz., as those which were unpredictable, even from a God's- 
eye perspective, from a complete knowledge of the subvenient base. That subvenient base provided no explanatory or predictive grounds for emergent properties precisely as emergent entities. Now it makes no difference for the relevance of this point that today we construe emergent properties ontologically and not epistemically. Even on the ontological construal, emergent properties are completely sui generis relative to the entities and processes at the subvenient base. In this regard, the following characterization by Timothy O'Connor and Hong Yu Wong (2005: pp. 665-6) may be taken as canonical:

An emergent property of type $\mathrm{E}$ will appear only in physical systems achieving some specific threshold of organized complexity. From an empirical point of view, this threshold will be arbitrary, one that would not be anticipated by a theorist whose understanding of the world was derived from theories developed entirely from observations of physical systems below the requisite complexity. In optimal circumstances, such a theorist would come to recognize the locally determinative interactive dispositions of basic physical entities. Hidden from his view, however, would be the tendency . . . to generate an emergent state.

For these reasons, $\mathrm{P}(\mathrm{C} / \mathrm{N} \& \mathrm{k})$ (where $\mathrm{k}$ is background knowledge) is so low as to approximate zero. In my book I show why it is question-begging and ad hoc for someone simply to label the existence of mental states (or their correlations with physical states) as a basic, naturalistic fact in need of no explanation.

Now consider the following:

$$
\begin{aligned}
& \underline{\mathrm{P}(\mathrm{T} / \mathrm{C} \& \mathrm{k})}=\underline{\mathrm{P}(\mathrm{T})} \times \underline{\mathrm{P}(\mathrm{C} / \mathrm{T} \& \mathrm{k})} \\
& \mathrm{P}(\mathrm{N} / \mathrm{C} \& \mathrm{k}) \quad \mathrm{P}(\mathrm{N}) \mathrm{P}(\mathrm{C} / \mathrm{N} \& \mathrm{k})
\end{aligned}
$$

The key probability for AC is not the prior probability of theism (and, I assume, the ratio of which it is a part). A low prior probability of theism does not by itself undercut AC. Even if that probability is low, it could be offset by an extremely low $\mathrm{P}(\mathrm{C} / \mathrm{N} \& \mathrm{k})$ which would, in turn, make the key ratio be $\mathrm{P}(\mathrm{C} / \mathrm{T} \& \mathrm{k})$ over $\mathrm{P}(\mathrm{C} / \mathrm{N} \& \mathrm{k})$. And that is what an advocate of AC should argue, for even if $\mathrm{P}(\mathrm{T})$ and $\mathrm{P}(\mathrm{C} / \mathrm{T} \& \mathrm{k})$ are somewhat low, the really low factor is $\mathrm{P}(\mathrm{C} / \mathrm{T} \& \mathrm{k})$ which, as I said above, approximates zero. And it is this probability that is crucial to the Bayesian version of AC. 
Finally, Oppy criticizes premises (1) and (5) of the deductive form of AC:

(1) Mental events are genuine non-physical mental entities that exist. (5) The explanation for these correlations (between mental/physical state types) is either a personal explanation or a natural scientific explanation.

Taking these in reverse order, Oppy argues against (5) that the options are not exhaustive. Accordingly, he suggests that there are naturalist theories, currently opaque to our cognitive capacities, which will say that the correlation of physical properties to mental properties is metaphysically necessary and such theories are neither natural scientific nor personal.

Oppy does not specify which theories he has in mind, but given his general contours, I think that the views of Timothy O'Connor represent the best specification of what Oppy has in mind. Briefly, there are two aspects to O'Connor's view. First, the causal powers of properties are essential aspects of those properties and, thus, belong to properties with an absolute, metaphysical necessity. The causal potentialities of a property are part of what constitutes the property's identity (O'Connor 2000: pp. 70-71, 117-118). It is in this sense, that in the right circumstances, a subvenient property necessitates an emergent property. By way of application, properties constitutive of consciousness are emergent in this sense (O'Connor 2000: pp. 115-123). Second, according to O'Connor, if an emergent property is depicted in such a way as to be contingently linked to the base properties causing it to emerge, then apart from an appeal to God's contingent choice that things be so and to God's stable intention that they continue to be so, there will be no explanation for the link itself or its constancy (O’Connor 2000: pp. 70-71).

With this in mind, I have two responses to Oppy's argument. First, I think it confuses an efficient causal explanation for the fact that some phenomenon obtains with an ontological analysis of emergence that does not remove the need for the former. Even if we grant some necessitation account such as O'Connor's, we are still left without an explanation as to why the causal underpinnings of emergent mental properties obtained as opposed to alternative physical conditions. And, it could be argued, the two rivals for explaining this fact would be a natural scientific and a personal one. To put the point differently, an emergent necessitation 
account will, in some sense, "explain" why an emergent property obtains by analyzing it as being necessitated by its subvenient base. But that does not explain why the base itself obtained. So the necessitation account does not, by itself, justify setting aside the dilemma of efficient causal explanation between natural scientific and personal explanation.

Second, in spite of what Oppy claims, the connection between mental and physical properties is contingent and not metaphysically necessary. Jaegwon Kim has provided an analysis of the dialectical situation we have reached (Kim 2006: pp. 229-33). According to Kim, while not conclusive, a very substantial case can be raised against the emergent necessitation view based on widely shared, plausible, commonsense intuitions that do not depend epistemically on a prior commitment to dualism. By contrast, Kim says that the only considerations in favor of emergent necessitation might very well be accused of begging the question because they all seem to depend upon a prior commitment to physicalism. I leave to the reader to ponder this stage of the dialectic, but I believe that, given contingency, O'Connor's remark about the need for theistic explanation here is right on target.

Regarding (1), I have little to say. I refer the reader to his rebuttal of my brief case for property/event dualism. I found it significantly wanting. Further, one major goal of my book was to supply intellectual pressure for naturalists to deny (1) and embrace strict physicalism. For some, this will be a small price to pay. For what I believe will be a growing number of others, such a denial is too steep a price to pay, and it will favourably be seen as fodder for a reductio against naturalism.

\section{GOD, CONSCIOUSNESS AND CHEMICAL EMERGENCE}

Oppy seems to think that my account of emergent properties ("given his apparent assumption that anything beyond 'structural constitution' is emergent") makes it likely that I am committed to chemical emergence relative to physics, and, given this, he asks why I do not consider chemical emergence, every bit as much as consciousness, a problem in need of a theistic explanation. Says Oppy, "I think that it is very hard to give a precise account on which the 'emergence' of consciousness from matter is more mysterious or surprising than the 'emergence' of the properties of 
water from the properties of hydrogen and oxygen; at the very least, we are owed some further explanation of why it is that chemistry is not 'sui generis, simple, intrinsically characterisable and new relative to [physics] (Oppy: p. 201)."

I offer three responses to Oppy's remarks. First, he does not give us an example of chemical emergence and I am skeptical that there are such. While I am open to counter examples, I think all chemical properties are either additive sums of features at the micro-physical level or else structurally supervenient on micro-physics.

Second, let's grant that there are chemically emergent properties. By their very nature, emergent properties are utterly novel, unpredictable and inexplicable in light of their subvenient base, and as a result, there are no grounds whatsoever for claiming that emergent properties are somehow necessitated by their bases. To be sure, we rightly have a Humean habit of expecting constant conjunction here based on past experience, but constant conjunction with respect to emergent and subvenient properties provides no grounds for thinking the former are necessitated by the latter. However, we do have grounds in the form of widespread, commonsense intuitions that the connection between emergent properties and their subvenient bases is contingent. I have already pointed this out with respect to mental properties, and since we do not have before us clear examples of chemical emergence, let us consider secondary qualities and, for the purposes of illustration, construe them as mind-independent, irreducible, emergent properties. In this case, it is quite easy, based on (defeasible) strong conceivability, to generate thought experiments in which an inversion of secondary qualities obtains. We are, then, prima facie justified in believing such states of affairs are metaphysically possible. Now recall Timothy O'Connor's remark that if an emergent property is depicted in such a way as to be contingently linked to the base properties causing it to emerge, then apart from an appeal to God's contingent choice that things be so and to God's stable intention that they continue to be so, there will be no explanation for the link itself or its constancy. In this way, contrary to Oppy, I see no reason why a theistic argument from chemical emergence (if such there be) could not be plausibly advanced.

Third, let us grant for the sake of argument that a theistic argument from chemical emergence is not plausible. Oppy challenges me to provide an account of why conscious emergence, but not chemical emergence, 
provides the basis of a theistic argument. To answer this, we need to step back a minute and consider the impact of the presence of a rival hypothesis on the evaluation of a hypothesis in question. An important factor in theory acceptance-scientific or otherwise-is whether or not a specific paradigm has a rival. If not, then certain epistemic activities, e. g., labelling some phenomenon as basic for which only a description and not an explanation is needed, may be quite adequate not to impede the theory in question. But the adequacy of those same activities can change dramatically if a sufficient rival position is present.

The types of entities postulated, along with the sorts of properties they possess and the relations they enter should be at home with other entities in the theory, and, in this sense, be natural for the theory. Some entity (particular thing, process, property, or relation) e is natural for a theory $\mathrm{T}$ just in case either e is a central, core entity of $\mathrm{T}$ or e bears a relevant similarity to central, core entities in e's category within T. If $\mathrm{e}$ is in a category such as substance, force, property, event, relation, or cause, e should bear a relevant similarity to other entities of $\mathrm{T}$ in that category. This is a formal definition and the material content given to it will depend on the theory in question.

Moreover, given rivals $\mathrm{R}$ and $\mathrm{S}$, the postulation of $\mathrm{e}$ in $\mathrm{R}$ is ad hoc and question-begging against advocates of $S$ if e bears a relevant similarity to the appropriate entities in $S$, and in this sense is "at home" in $S$, but fails to bear this relevant similarity to the appropriate entities in $\mathrm{R}$. The notion of "being ad hoc" is notoriously difficult to specify precisely. It is usually characterized as an intellectually inappropriate adjustment of a theory whose sole epistemic justification is to save the theory from falsification. Such an adjustment involves adding a new supposition to a theory not already implied by its other features. In the context of evaluating rivals $\mathrm{R}$ and $\mathrm{S}$, the principle just mentioned provides a sufficient condition for the postulation of e to be ad hoc and question-begging.

The issue of naturalness is relevant to theory assessment between rivals in that it provides a criterion for advocates of a theory to claim that their rivals have begged the question against them or adjusted their theory in an inappropriate, ad hoc way. And though this need not be the case, naturalness can be related to basicality in this way: Naturalness can provide a means of deciding the relative merits of accepting theory $\mathrm{R}$, which depicts phenomenon e as basic, vs. embracing $\mathrm{S}$, which takes 
e to be explainable in more basic terms. If e is natural in $\mathrm{S}$ but not in $\mathrm{R}$, it will be difficult for advocates of $\mathrm{R}$ to justify the bald assertion that $\mathrm{e}$ is basic in $\mathrm{R}$ and that all proponents of $\mathrm{R}$ need to do is describe e and correlate it with other phenomena in $\mathrm{R}$ as opposed to explaining e. Such a claim by advocates of $\mathrm{R}$ will be even more problematic if $\mathrm{S}$ provides an explanation for e.

Now conscious properties are basic for theism in a way that (alleged) emergent chemical properties are not in that the former and not the latter characterize the fundamental, core entity in a theistic paradigm. There is no need for a theist to account for the origin of consciousness per se since he takes consciousness to be basic. And the fact that consciousness appears in world history, is at home given theism in a way that chemical properties are not. This is why there are additional grounds for using the former in a theistic argument that fail to be present regarding the explanation of chemical emergent properties.

\section{CONCLUSION}

As I mentioned in the introduction, it is hardly surprising that Oppy is not persuaded by my presentation of AC, since he seems to be a hard person to persuade in general. The explosion of literature on behalf of theism in the last few decades has not moved him to consider $\operatorname{Pr}(\mathrm{T})$ as much higher than zero. He flatly states in his review that "there is no such thing as libertarian freedom (Oppy: p. 200)"; he does not say that, on balance, compatibilism is to be preferred to libertarianism or that libertarianism is less plausible than compatibilism. Apparently, all the defenses of libertarian freedom have had little impact on his assessment of libertarianism.

I believe others will be more open to AC, especially those naturalists who acknowledge there is a serious problem here for naturalism. I have in mind those thinkers like Jaegwon Kim who (1) are sensitive to the hard problem of consciousness and, relatedly, to emergentist questions (e.g., Why does pain instead of pleasure or no conscious property at all correlate with C fiber firing?) (Kim 2006: pp. 220-36, 282-305.), (2) accept certain emergent mental properties (those of phenomenal consciousness for Kim), and (3) recognize the limits of naturalistic explanation. Regarding 
(3), Kim observes that "if a whole system of phenomena that are prima facie not among basic physical phenomena resists physical explanation, and especially if we don't even know where or how to begin, it would be time to reexamine one's physicalist commitments (Kim 1998: p. 96.)" For Kim, genuinely non-physical mental entities are the paradigm case of such a system of phenomena. And in this context, to abandon physicalist commitments is to abandon naturalist ones, or so I argue in my book.

I have tried to respond to what I take are the crucial criticisms Oppy advances against my thesis. There are many criticisms he raises that I have not addressed. But life is short this side of the grave, and space is limited, so I must rest content with where things stand. I am honored to have someone of Oppy's stature criticize my work, even though I cannot follow him in his views. ${ }^{1}$

\section{BIBLIOGRAPHY}

Flew, Anthony and Varghese, Roy Abraham. (2007) There Is a God New York: HarperCollins.

Kim, Jaegwon. (1998) Mind in a Physical World Cambridge, MA: MIT Press.

Kim, Jaegwon. (2006) Philosophy of Mind: Second Edition Boulder, CO: Westview.

Lipton, Peter. (2000) "Inference to the Best Explanation" in W. H. NewtonSmith A Companion to the Philosophy of Science Malden, MA: Blackwell Publishers, 184-93.

Long, Jeffrey. (2010) Evidence of the Afterlife New York: HarperCollins.

Moreland, J. P. (2008) Consciousness and the Existence of God New York: Routledge.

Moreland, J. P. (2009a) "The Argument from Consciousness" in William Lane Craig, J. P. Moreland The Blackwell Companion to Natural Theology Malden, MA: Blackwell, 282-343.

Moreland, J. P. (2009b) The Recalcitrant Imago Dei London: SCM.

Nagel, Thomas. (1997) The Last Word New York: Oxford University Press.

O’Connor, Timothy. (2000) Persons \& Causes New York: Oxford University Press.

${ }^{1}$ I want to thank Garry DeWeese, Lydia McGrew, Timothy McGrew and William Lane Craig for their helpful suggestions on an earlier draft of the article. 
O'Connor, Timothy and Wong, Hong Yu. (2005) “The Metaphysics of Emergence” Nous 39, 658-78.

Oppy, Graham. (2011) "A Review of J. P. Moreland's Consciousness and the Existence of God" European Journal for Philosophy of Religion xxxx.

Plantinga, Alvin. (1993) Warrant and Proper Function Oxford: Oxford University Press.

Reppert, Victor. (2009) “The Argument from Reason" in William Lane Craig, J. P. Moreland The Blackwell Companion to Natural Theology Malden, MA: Blackwell, 344-90.

Smart, J. J. C. (1959) "Sensations and Brain Processes" Philosophical Review 68, 141-56.

Smith, Quentin. (2001) “The Metaphilosophy of Naturalism” Philo 4, 195-215. 